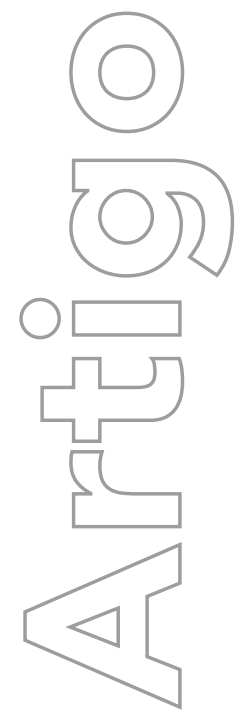

revista

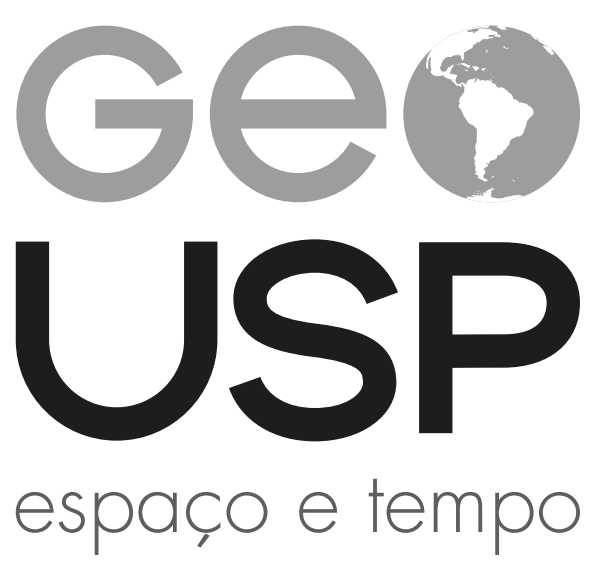

Volume $25 \cdot n^{\circ} 1$ (2021)

ISSN 2179-0892

\section{A geografia na formação dos professores: tempos e espaços nos cursos de pedagogia}

\author{
Samara Mirelly da Silva ${ }^{a}$ \\ a Universidade do Estado de Minas Gerais. \\ Divinópolis. Minas Gerais. Brasil \\ samara.mirelly@uemg.br \\ (1) 0000-0001-6650-9043 \\ Vicente de Paula Leãob \\ b Universidade Federal de São João del-Rei. \\ São João del-Rei. Minas Gerais. Brasil \\ leao@ufsj.edu.br \\ (1) $0000-0001-6949-2611$
}

e-142029

Como citar este artigo:

SILVA, S. M.; LEÃO, V. P. A geografia na formação dos professores: tempos e espaços nos cursos de pedagogia. Geousp, v. 25, n. 1, p. 1-16, e-142029, 2021. ISSN 2179-0892.

Disponível em: https://www.revistas.usp.br/geousp/article/ view/142029. doi: https://doi.org/10.11606/issn.2179-0892. geousp.2021.142029.

\section{(c)}

Este artigo está licenciado sob a Creative Commons Attribution 4.0 Licence 


\title{
A geografia na formação dos professores: tempos e espaços nos cursos de pedagogial
}

\section{Resumo}

Refletir sobre a formação inicial, o trabalho dos professores e a construção do conhecimento geográfico nos anos iniciais é fundamental para compreender aspectos do processo de alfabetização das crianças. Este texto é parte de uma pesquisa que analisou os direcionamentos dados à Geografia nos cursos de Pedagogia das Universidades Federais em Minas Gerais, no Brasil. Apoiada em Projetos Pedagógicos de Curso, matrizes curriculares e ementas, a pesquisa constatou que categorias de análise como lugar, paisagem, território e o próprio espaço geográfico figuram apenas eventualmente nos documentos citados. Entende-se ser basilar, para um trabalho crítico e reflexivo, que os professores conheçam a Ciência de referência e seus conceitos estruturadores para compreender a relevância de seu ensino e, assim, fazê-lo com maior autonomia.

Palavras-chave: Ensino. Geografia. Formação docente. Pedagogia. Anos iniciais do Ensino Fundamental.

\section{Geography in Teacher Training: times and spaces in Pedagogy Courses}

\begin{abstract}
Reflecting on the initial formation, the work of the teachers and the construction of the geographical knowledge in the Initial Years is of great importance for the understanding of aspects referring to the process of literacy of the students. The present text is part of a research that analyzed the directions given to Geography in the courses of Pedagogy of Federal Universities in Minas Gerais, Brazil. Based on the Pedagogical Course Projects, curricular matrices and menus, the research found that categories of analysis such as: place, landscape, territory
\end{abstract}

Este texto é um recorte da pesquisa desenvolvida no Programa de Pós-graduação em Geografia da Universidade Federal de São João del-Rei (UFSJ), em que se buscou compreender como são formados os futuros professores dos anos iniciais do ensino fundamental (Aief) nos cursos de Pedagogia (modalidade presencial) instalados nas Universidades Federais em Minas Gerais, no que se refere ao conhecimento geográfico. 
and geographic space itself appear eventually in the aforementioned documents. However, it is understood that it is basic, for a critical and reflexive work, for teachers to know the Science of reference and its structuring concepts to understand the relevance of performing their teaching and, therefore, to do it with greater autonomy.

Keywords: Teaching. Geography. Teacher training. Pedagogy. Early years of elementary Education.

\section{La geografía en la formación del profesorado: tiempos y espacios en los cursos de Pedagogía}

\section{Resumen}

La reflexión sobre la formación inicial, el trabajo de los docentes y la construcción del conocimiento geográfico en la Primera Infancia es de gran importancia para comprender aspectos relacionados con el proceso de alfabetización de los niños. Este texto es parte de una investigación que analizó las direcciones dadas a la Geografía en los cursos de Pedagogía en las Universidades Federales de Minas Gerais, Brasil. Con el apoyo de los Proyectos del Curso Pedagógico, matrices curriculares y menús, la investigación encontró que categorías de análisis como: lugar, paisaje, territorio y el propio espacio geográfico, eventualmente aparecen en los documentos antes mencionados. Se entiende fundamental, para un trabajo crítico y reflexivo, que los docentes conozcan la Ciencia de referencia y sus conceptos estructurantes para comprender la relevancia de llevar a cabo su docencia y así hacerlo con mayor autonomía.

Palabras clave: Docencia. Geografía. Formación de profesores. Pedagogía. Primeros años de la escuela primaria.

\section{Introdução}

Os Parâmetros Curriculares Nacionais de Geografia (Brasil, 1997) para as séries iniciais falam da importância da compreensão de conceitos a partir das experiências vividas pelos alunos. Contudo, dificilmente, os livros didáticos disponíveis para essa etapa de aprendizagem, principal material utilizado nas aulas de Geografia, abordam temas locais, conforme criticam as professoras (Silva; Leão, 2016). 
Assim, uma possível falta de ponderação docente faz com que, de acordo com Callai (2010, 2011, 2016), ao discutir o Plano Nacional do Livro Didático (PNLD) no âmbito do conjunto das políticas públicas que orientam a educação escolar brasileira, o professor passe a ter o livro didático como orientador de seu trabalho, quando, muitas vezes, as atividades e exercícios propostos são feitos apenas para cumprir uma orientação curricular oficial.

Dessa maneira, parte-se da premissa de que é necessário haver uma formação inicial docente que capacite o futuro professor a realizar um trabalho autônomo, contextualizado e significativo nos anos iniciais do Ensino Fundamental (Aief). Consequentemente, que este possa ser sujeito de seu trabalho, e não simplesmente um reprodutor de ações definidas externamente a ele (Callai, 2010).

Acredita-se que compreender como os professores dos anos iniciais do Ensino Fundamental são formados pelos cursos de Pedagogia para lecionar os conteúdos das áreas específicas que compõem o currículo da Educação Básica, entre elas, a Geografia, de certa forma, diz das opções que eles adotam em sua prática. Pode-se pensar também na ausência/presença de determinados saberes nos Aief, tendo em vista que a clareza teórico-metodológica é basilar para que o professor contextualize seus saberes, os dos alunos e os sobre o mundo a sua volta (Callai, 2005, p. 231).

Nessa perspectiva, o procedimento metodológico adotado nessa etapa da pesquisa foi a análise documental, sobretudo, de projetos pedagógicos de curso (PPC), matrizes curriculares e ementas de disciplinas relacionadas à Geografia. Considerando a importância desses documentos nas ações e nos planos de ação nos cursos formadores, bem como para definir o perfil profissional que se almeja constituir, analisá-los é uma forma de apreender os aportes que embasam a formação do docente no âmbito da escolarização inicial.

Busca-se, assim, entender como se estrutura o ensino de Geografia na matriz curricular dos cursos superiores de Pedagogia. Pretende-se, consequentemente, refletir sobre como os graduandos aprendem Geografia para ensiná-la nos Aief, bem como almeja-se avaliar se o que dizem os Parâmetros Curriculares Nacionais de Geografia (Brasil, 1997) está ocorrendo nos cursos formadores. Ou seja, se as categorias de análise do conhecimento geográfico (lugar, paisagem, território e o próprio espaço geográfico) que devem ser trabalhados nos Aief, estão presentes nesses cursos.

Cumpre esclarecer, entretanto, que, de acordo com García (1999), a formação inicial representa uma dimensão do ensino intencional voltado para a profissionalização dos sujeitos encarregados de educar as novas gerações. Embora não deva fornecer "produtos acabados" aos futuros professores, constitui-se na primeira fase de um longo e diferenciado processo de desenvolvimento profissional (García, 1997, grifo nosso), e assim deve ser compreendida.

Afinal, compartilha-se das ideias de António Nóvoa (1997, p. 12) quando, na nota de apresentação do livro Os professores e a sua formação, afirma: "Os professores vivem tempos difíceis e paradoxais. Apesar das críticas e das desconfianças em relação às suas competências profissionais, exige-lhes quase tudo. Temos de ser capazes de pensar a nossa profissão".

\section{Formação docente nos cursos de pedagogia}

A atual estrutura didática da educação formal no Brasil, proposta pela Lei n. 9.394 (Brasil, 1996), ou Lei de Diretrizes e Bases da Educação Nacional (LDB), em seu Artigo 21, afirma que a educação escolar compõe-se da Educação Básica (Educação Infantil e Ensinos Fundamental e Médio) e da Educação Superior (graduação e pós-graduação). 
Segundo as Diretrizes Curriculares Nacionais Gerais para a Educação Básica (Brasil, 2013, grifo nosso), a Educação Básica abrange, em regra, as seguintes etapas:

I - a Educação Infantil, que compreende: a Creche, englobando as diferentes etapas do desenvolvimento da criança até 3 (três) anos e 11 (onze) meses; e a Pré-Escola, com duração de 2 (dois) anos.

II - o Ensino Fundamental, obrigatório e gratuito, com duração de 9 (nove) anos, é organizado e tratado em duas fases: a dos 5 (cinco) anos iniciais e a dos 4 (quatro) anos finais.

III - o Ensino Médio, com duração mínima de 3 (três) anos.

Na década de 1990, segundo a LDB (Brasil, 1996), profissionais que pretendessem lecionar na Educação Infantil ou nos primeiros ciclos do Ensino Fundamental poderiam estudar em dois lugares: num curso Normal Superior, dentro dos Institutos Superiores de Educação (ISE), e em cursos de Pedagogia, em universidades ou centros universitários.

Após reivindicações e negociações entre os diversos atores em cena na discussão das políticas públicas de formação de profissionais da educação para que os cursos de Pedagogia tivessem suas próprias Diretrizes (Scheibe, 2008), em 16 de maio de 2006, no Diário Oficial da União, foi publicada a Resolução CNE/CP n. 1 (Brasil, 2006), que institui as Diretrizes Curriculares Nacionais para o curso de graduação em Pedagogia, licenciatura² (DCNP).

Embora ainda criticada, essa publicação mostra a tentativa de colocar a docência como a base profissional do pedagogo, consequentemente devolvendo aos cursos superiores de Pedagogia a responsabilidade pela formação dos profissionais que atuarão na Educação Infantil e anos iniciais do Ensino Fundamental.

Logo, as DCNP atestam, em seu Artigo 4, que o curso de Pedagogia destina-se à formação de professores para exercer funções de magistério na Educação Infantil e nos anos iniciais do Ensino Fundamental, nos cursos de Ensino Médio, na modalidade Normal, de Educação Profissional, na área de serviços e apoio escolar e em outras áreas nas quais sejam previstos conhecimentos pedagógicos (Brasil, 2006, p. 2). A formação inicial nos cursos de Pedagogia tem por base, portanto, o tripé: Docência, Gestão e Pesquisa.

Ainda segundo as Diretrizes Curriculares, o curso de Pedagogia poderá formar também o pesquisador e gestor educacional para atuar na escola e em espaços não escolares, bem como na educação profissional na área de serviços e apoio escolar (Brzezinski, 2008, p. 1160). Assim, o profissional formado nesses cursos poderá atuar igualmente na docência e na organização do trabalho pedagógico, bem como na pesquisa e difusão do conhecimento do campo educacional em contextos escolares e não escolares.

No que se refere à docência para a Educação Infantil e os Aief, a Resolução afirma, no Artigo 5, que o egresso do curso de Pedagogia deverá estar apto, entre 16 outros itens, a ensinar Língua Portuguesa, Matemática, Ciências, História, Geografia, Artes e Educação

2 Instituídas pelo CNE/CP n. I (Brasil, 2006), nos termos explicitados nos Pareceres CNE/CP n. 5/2005 e n. 3/2006 e sendo responsáveis, portanto, por definir "os princípios, condições de ensino e de aprendizagem, procedimentos a serem observados em seu planejamento e avaliação, pelos órgãos dos sistemas de ensino e pelas instituições de educação superior do país". 
Física, de forma interdisciplinar e adequada às diferentes fases do desenvolvimento humano, uma vez que são esses os componentes curriculares da base comum dessa etapa da Educação Básica.

Logo, procurou-se obter um panorama do que tem sido proposto pelas instituições de ensino superior em seus cursos de Pedagogia no que diz respeito ao ensino de Geografia como área específica constituinte do currículo dos anos iniciais do Ensino Fundamental.

$O$ estado de Minas Gerais é o que tem o maior número de universidades federais, 11 ao todo. Isso significa mais de 50\% das universidades públicas federais situadas na região Sudeste e 17,46\% do total (Silva, 2017).

Minas Gerais fica na região Sudeste do Brasil, cuja capital, Belo Horizonte, dista aproximadamente $755 \mathrm{~km}$ de Brasília. $\bigcirc$ estado tem 853 municípios e uma população de 19.597.330 habitantes, segundo o último censo demográfico do Instituto Brasileiro de Geografia e Estatística (IBGE, 2010). Sua população está distribuída por uma área de 586.519 .727 km², sendo, portanto, de $33,41 \mathrm{hab} / \mathrm{km}^{2}$ a densidade demográfica mineira.

Entre as universidades federais instaladas nesse estado, apenas duas não ofereciam curso de Pedagogia, modalidade presencial. Todas as demais, Universidade Federal de Alfenas (Unifal), Universidade Federal de Juiz de Fora (UFJF), Universidade Federal de Lavras (Ufla), Universidade Federal de Minas Gerais (UFMG), Universidade Federal de Ouro Preto (UFOP), Universidade Federal de São João del-Rei (UFSJ), Universidade Federal de Uberlândia (UFU), Universidade Federal dos Vales do Jequitinhonha e Mucuri (UFVJM) e Universidade Federal de Viçosa (UFV), e seus respectivos cursos de Pedagogia se tornaram lócus da pesquisa, sendo identificados pelas letras A, B, C, D, E, F, G, H, I e J, não correspondendo à ordem alfabética em que aparecem acima.

A IFES G tem dois cursos de Pedagogia, modalidade presencial, instalados em cidades distintas. Estes foram identificados, destarte, por G1 e G2. Portanto, perfaz-se um total de dez cursos pesquisados.

Dos dez cursos de Pedagogia, dois não disponibilizavam seus PPC na internet (nas páginas oficiais/institucionais) e nem quando solicitados via telefonemas e e-mails. Analisaram-se, assim, outras informações e documentos oficiais. $\bigcirc$ Curso D argumentou que o PPC estava em fase de reelaboração e o segundo, C, que o curso é recente e seu PPC, ainda em trâmite legal, não poderia ser divulgado. Embora o Projeto Pedagógico do Curso E também estivesse em fase de reelaboração, ele nos foi gentilmente cedido, já que não estava disponível na rede mundial de computadores.

\section{Disciplinas das áreas específicas nos cursos de pedagogia analisados}

Tal como Libâneo (2010) constatou ao investigar o lugar dado à Didática e ao ensino das áreas específicas nos cursos de formação profissional de professores dos Aief, nota-se que as disciplinas de metodologias específicas estão presentes em todos os cursos pesquisados, embora com diferentes denominações e números de disciplinas oferecidas.

$\mathrm{Na}$ medida em que as Diretrizes Curriculares Nacionais para esses cursos são amplas e a estruturação curricular fica a cargo de cada instituição (Gatti; Nunes, 2009), nota-se, a respeito das unidades curriculares oferecidas, uma certa discrepância quanto ao número de disciplinas, que varia de 25 a 47 obrigatórias, sendo a média de 41 disciplinas regulares por curso 
(excetuando-se as destinadas a trabalho de conclusão de curso, formação livre, estágio supervisionado, atividades acadêmico-científico-culturais e correlatas).

Consideram-se disciplinas regulares aquelas que impreterivelmente devem ser realizadas para a integralização do curso, sendo definidas na matriz curricular que compõe o PPC e estabelecidas por seus respectivos Colegiados.

Entre as 410 unidades curriculares catalogadas como regulares nos dez cursos de Pedagogia, modalidade presencial, instalados nas universidades federais em Minas Gerais, 75 respondem pela formação inicial dos pedagogos nas áreas que compõem o currículo da Escola Básica, o que corresponde a aproximadamente $18 \%$ do total. ${ }^{3}$ Assiste-se, ainda, a uma melhor aceitação da Língua Portuguesa e da Matemática, haja vista que, destas, 30 (40\%) concernem a essas áreas. Nesse contexto, as 45 restantes devem ocupar-se do ensino de Artes, Ciências, Educação Física, Geografia e História.

Em relação ao conhecimento geográfico, contabilizaram-se 11 unidades curriculares oferecidas, o que significa aproximadamente 3\% das disciplinas tidas como indispensáveis e 14,6\% das dirigidas às áreas específicas nos cursos de Pedagogia.

Segundo Libâneo (2010), as metodologias específicas são as disciplinas que suprem o futuro professor com bases metodológicas e procedimentais para ensinar os conteúdos do currículo dos Aief. Nesse sentido, observou-se que a maioria dos cursos, oferece apenas uma disciplina obrigatória destinada a cada uma das áreas que compõem o currículo da educação básica em que os egressos poderão atuar.

\section{O ensino de Geografia segundo os documentos balizadores dos cursos}

Conforme apresentado em outro momento, dois cursos não disponibilizaram o Projeto Pedagógico: C e D. Avaliaram-se, assim, a Matriz Curricular e outros documentos dispostos por estes nas páginas oficiais das instituições na internet. Consideraram-se também os dados presentes na Matriz Curricular 2015/1 do Curso E, disponível on-line em sua página oficial, tendo em vista que há conflitos entre esta e o PPC de Pedagogia (2008). ${ }^{4}$ Optou-se por usá-la por ser mais atual e porque, conforme já posto, o PPC está em fase de reconstrução.

Das unidades curriculares ministradas na licenciatura em Pedagogia do curso $\mathrm{H}$, nenhuma apresenta a nomenclatura "Geografia". Destas, a única que se aproxima do conhecimento geográfico é o Componente Curricular: Princípios e Métodos do Ensino de Ciências Humanas; portanto, aqui analisada como a disciplina responsável por lidar com a Geografia na formação dos pedagogos para o exercício da docência nos anos iniciais do Ensino Fundamental.

3 Em alguns cursos, é obrigatório que, no decorrer da formação inicial, os graduandos escolham as disciplinas que cursarão entre as oferecidas como eletivas ou opcionais. Entretanto, quais são elas depende em grande medida da predileção dos próprios graduandos, o que torna complexo conjeturar a esse respeito. Nesse sentido, consideram-se nesta pesquisa apenas as colocadas como regulares na matriz curricular dos cursos, o que muda um pouco esse número, de acordo com a escolha dos estudantes.

4 Entre tais diferenças, estão a exclusão da Matriz Curricular das seguintes disciplinas do PPC: "Geografia e História: Conteúdos e Metodologias" (60 horas), "Prática de Ensino de Geografia" (60 horas) e "Prática de Ensino de História" (60 horas). Na atual estrutura, elas foram transformadas em "História: Conteúdos, Metodologia e Práticas de Ensino" (90 horas) e "Geografia: Conteúdos, Metodologias e Práticas de Ensino" (90 horas). 
Apenas um curso (curso A) oferece duas disciplinas regulares voltadas ao ensino de Geografia, com 75 e 45 horas, oferecidas no sétimo e oitavo períodos, consecutivamente. $\bigcirc$ Curso B oferece também duas unidades curriculares, sendo uma eletiva, "de aprofundamento", conforme seu PPC e outra regular.

No que tange à denominação dos cursos pesquisados, apenas duas se assemelham: "Geografia: Fundamentos e Metodologias" (A) e "Fundamentos e Metodologia do Ensino de Geografia" (D). Tendo em vista que o acréscimo dos termos teórico(-metodológicos) e didática (fundamentos e didática) pode alterar o sentido que o título busca abarcar, consideraram-se distintos. Assim, oito dos dez cursos dão às unidades curriculares nomes diferentes.

Gatti e Nunes (2009, p. 21), tendo encontrado grande variedade de nomenclatura em cada curso e entre os próprios cursos de Pedagogia, afirmam que tal fato sinaliza que o projeto de cada instituição procura sua vocação em diferentes aspectos do conhecimento, com enfoque próprio, o que se reflete na denominação das disciplinas. Não foi excluída, portanto, essa possibilidade também nos cursos de Pedagogia lotados nas universidades em Minas Gerais.

Evidencia-se que os cursos $\mathrm{C}$ e Gl tratam duas áreas do conhecimento agrupadas em uma única disciplina: "Metodologia do Ensino de História e Geografia", assim como o Curso H, em "Princípios e Métodos do Ensino de Ciências Humanas".

Tal junção também foi verificada por Libâneo (2010), que analisou 25 matrizes curriculares de cursos de Pedagogia no estado de Goiás. No estudo, nove delas traziam Geografia e História congregadas em uma só disciplina e em suas ementas havia "raras menções aos temas e procedimentos investigativos próprios dessas áreas" (Libâneo, 2010, p. 571).

Embora as Diretrizes Curriculares Nacionais para o Ensino Fundamental de nove anos (Brasil, 2013) apresentem os componentes curriculares obrigatórios do Ensino Fundamental organizados por área de conhecimento, ${ }^{5}$ entende-se que o campo das Ciências Humanas nessa etapa, composto por História e Geografia, exige abordagem específica dos conteúdos correspondentes, que podem (e devem) ter um tratamento interdisciplinar nos cursos de formação docente.

Lembrando que a perspectiva interdisciplinar está posta no artigo 50 da Resolução CNE de 01/05/2006 e que ela exige dos professores conhecimento aprofundado sobre cada disciplina para identificação de possibilidades de diálogos com os demais saberes, em programas de educação continuada, voltados para professores de diferentes disciplinas da educação básica, tem-se constatado a dificuldade e complexidade desta construção interdisciplinar, que requer como primeiro movimento um olhar mais cuidadoso em cada disciplina (Gatti; Nunes, 2009, p. 37).

Essa abordagem remete à fala de uma professora ao elencar as dificuldades encontradas para o ensino de Geografia nos Aief: "Saber o que é Geografia. O que é História. Temos

5 A saber: I - Linguagens: (a) Língua Portuguesa, (b) Língua materna, para populações indígenas, (c) Língua Estrangeira moderna, (d) Arte, (e) Educação Física; II - Matemática; III - Ciências da Natureza; IV - Ciências Humanas: (a) História, (b) Geografia; V - Ensino Religioso. 
dificuldades. A gente não sabe muito bem o que é o quê" (informação verbal). ${ }^{6}$ Muitas vezes, a falta dessa clareza teórico-metodológica interfere negativamente no tratamento dessas áreas na Escola Básica, sobretudo nos Aief; ainda mais quando, no momento da formação inicial, essas diferenciações entre uma e outra são ignoradas.

Com relação ao período, grande parte delas é oferecida na segunda metade do curso, sendo que, em dois deles, são oferecidas no último período, quando já terminou a maior parte da carga horária relativa ao Estágio Supervisionado e também estão na fase final as atividades de trabalho de conclusão de curso (TCC).

Entende-se que, se trabalhadas ao decorrer dos cursos formadores, essas disciplinas poderiam dar subsídio teórico-metodológico às reflexões em diferentes momentos. Munidos desse conhecimento, os graduandos poderiam com mais facilidade ter práticas interdisciplinares, bem como análises mais direcionadas quanto ao tratamento dado à Geografia durante o estágio supervisionado e mesmo intervenções pedagógicas em ambientes escolares. Conforme ilustra a fala de um docente formador, responsável por lecionar a unidade curricular relativa à Geografia em um dos cursos pesquisados:

[...] os alunos descobrem a importância da geografia e até desenvolvem TCC relacionados à geografia. No ano de 2015, coordenei, junto com outras professoras, um evento envolvendo Geografia, Ciências e História, mas foi uma atividade pontual que exigiu muito trabalho, mas foi bem produtiva e os alunos apresentaram suas práticas envolvendo as três áreas. Isto deveria ser uma prática comum [...] (grifos nossos).

Percebe-se que, além do tempo dedicado a essa instrução, que possibilitou a ocorrência dessa "prática pontual" que forneceu outras opções e possibilidades na trajetória acadêmica dos graduandos, a atuação do professor formador pode fazer toda a diferença para um ensino mais crítico e contextualizado de Geografia nos cursos de Pedagogia. Assim, entende-se que a valorização dessa área do conhecimento parte também da conduta adotada pelo professor formador, que, ao ministrar a unidade curricular voltada a esse fim, tenha também por objetivo mobilizar e despertar nos graduandos o interesse por essa área do conhecimento.

Por fim, a média da carga horária total das unidades curriculares que abordam a Geografia nos cursos de Pedagogia é de 70 horas, sendo cinco com 60 horas e uma com menos. Vale ressaltar mais uma vez que duas delas abordam a "Metodologia do Ensino de História e Geografia" na mesma unidade curricular, com cargas horárias de 60 e 120 horas; e outra "Princípios e Métodos do Ensino de Ciências Humanas", com 75 horas/aula.

Ainda a respeito da carga horária dessas disciplinas, Braga (2006, p. 233) elucida que essa discussão deve ser mais aprofundada, haja vista que somente o aumento de horas-aula não garante que os problemas da formação inicial sejam resolvidos, uma vez que, para a autora, " [...] Se o modelo da racionalidade técnica continuar a imperar nas licenciaturas, o aumento do tempo das disciplinas didáticas será de pouca utilidade". A racionalidade técnica, de acordo com Gómez (1997, p. 97):

6 Em reunião com as Coordenadoras Pedagógicas dos Aief na Secretaria Municipal de Educação de São João del-Rei, MG, em 2013, realizada no âmbito do Projeto de Extensão, desenvolvido pelos autores deste texto. 
Trata-se de uma concepção epistemológica da prática, herdada do positivismo, que prevaleceu ao longo de todo séc. XX, servindo de referência para a educação e socialização dos profissionais em geral e dos docentes em particular. Segundo o modelo da racionalidade técnica, a atividade do profissional é, sobretudo, instrumental, dirigida para a solução de problemas mediante a aplicação rigorosa de teorias e técnicas científicas.

Com intuito de apreender como o conhecimento geográfico é trabalhado no interior dessas unidades curriculares, examinaram-se suas ementas.

\section{Ementas das disciplinas de geografia}

Em tempo, antes de apresentar as ementas dos cursos pesquisados, cumpre esclarecer a essencialidade desse documento nos cursos de formação. Conforme Gatti e Nunes (2009, p. 32-33), a adequação do texto das ementas à abordagem central de conteúdos e objetivos a ser trabalhados é relevante pelo menos por três motivos: primeiro, por revelar que o próprio professor conhece e sabe sinteticamente o conjunto de temas a ser abordados na formação dos futuros educadores; depois, para comunicar aos alunos os compromissos da disciplina, auxiliando no acompanhamento do currículo. A esse respeito, as autoras compreendem que o acesso dos alunos aos programas de ensino tem viabilizado movimentos discentes mais fundamentados e críticos em relação ao trabalho dos professores; e, por último, ainda que menos diretamente relevante para o bom andamento do currículo, a redação adequada de ementas ajuda pesquisadores a se aproximarem de forma mais precisa do trabalho proposto em diferentes projetos pedagógicos.

Nessa perspectiva, analisaram-se ementas, programas analíticos ou fichas de disciplinas que tratam do ensino de Geografia nos cursos de Pedagogia voltadas para o conhecimento geográfico. Com tal análise, buscou-se saber também se os conceitos estruturadores do conhecimento geográfico estão presentes nesses cursos, uma vez que o texto dos PCN de Geografia (Brasil, 1997) para as séries iniciais afirma que, embora o espaço geográfico seja o objeto de estudo da Geografia, as categorias paisagem, lugar e território devem estar presentes nessa etapa da escolarização.

Apesar de disponibilizarem os PPC, os cursos G1, G2 e I não trazem, nesse documento, as ementas nem a bibliografia básica adotada para o desenvolvimento das disciplinas. As ementas referentes ao primeiro e segundo foram conseguidas em suas páginas na internet em link específico "Fichas de Disciplinas". O terceiro, via contato direto com a coordenação do curso.

C Curso C, por estar em fase de implantação, não havia oferecido a disciplina, proposta para o sexto período, bem como não contava com a ementa nem com o docente responsável por ministrá-la designado. Já para análise do curso D, utilizou-se a Matriz Curricular versão 2013/1 (2009/1) disposta na rede mundial de computadores, em que há possibilidade de acesso das ementas. Por conseguinte, dos dez cursos de Pedagogia pesquisados, apenas um não teve sua ementa analisada e, como dois cursos oferecem duas disciplinas voltadas à Geografia (uma de caráter eletivo e outra regular), perfez-se um total de onze ementas avaliadas nesse momento.

Segundo Gatti e Nunes (2009, p. 31), e o que também se observou na pesquisa, não há padrão comum para a elaboração das ementas, o que passa, inclusive, pelo entendimento a respeito de sua própria redação. Segundo as autoras: "A grande maioria dos proponentes 
entende que devem registrar uma lista de temas que formam o conjunto dos conteúdos trabalhados no período, um semestre ou um ano".

Ainda para as pesquisadoras, os textos identificados como ementas são resumos que deveriam facilitar o acesso de alunos e demais interessados às intenções de um curso específico. Dessa forma, colocam três características mais encontradas nelas. Entendidas como listas de conteúdos, ora como explicitação de certas concepções (ou objetivos gerais) em apenas um parágrafo, ou, ainda, compreendidas tendo em vista expressar concepções e finalidades dos componentes curriculares.

Nas ementas estudadas, percebe-se a predominância da primeira característica. Isto é, entende-se pelo exame de suas enunciações que elas são entendidas como enumeração de conteúdos. Veja-se ementa do Curso D:

Mediação das teorias geográficas para a Educação Infantil e anos iniciais do Ensino Fundamental. Leitura geográfica do mundo contemporâneo. Sujeito e objeto do conhecimento geográfico: os conceitos e categorias geográficas nos diferentes contextos. A produção e a apropriação da linguagem gráfica/categórica, os significados e representações.

Não por acaso, Gatti e Nunes (2009, p. 38) concluíram que as ementas voltadas para o ensino das áreas específicas nos cursos de Pedagogia "registram uma preocupação com teorias de ensino e com justificativas sobre por que ensinar, mas só de forma muito incipiente registram o que e como ensinar". Haja vista que a pauta mais realçada nas ementas foi a que diz respeito a correntes, teorias e concepções de Geografia (ou de seu ensino), especialmente nos anos iniciais do Ensino Fundamental.

Atenta-se, também, para o fato de algumas ementas apresentarem certa imprecisão ou insuficiências na sua redação para o entendimento do tratamento do conhecimento geográfico que será dispensado na unidade curricular, como no caso da ementa da disciplina "Princípios e Métodos do Ensino de Ciências Humanas" oferecida no Curso H:

Conhecimento e uso de fontes históricas com recursos didáticos. Análise e práticas educativas. Análise de material didático no ensino de ciências humanas. Concepção e instrumentos de avaliação no ensino de práticas interdisciplinares: produção de material didático.

texto da ementa é genérico (no dizer de Gatti e Nunes, 2009) e não permite identificar os conteúdos específicos tratados na disciplina. Cumpre ressaltar que essa é a ementa da única disciplina do curso voltada para o ensino de Geografia e sequer a Bibliografia da unidade curricular corrobora para o entendimento do conhecimento geográfico especificamente.

\section{A presença dos conceitos estruturadores do conhecimento geográfico nas ementas de geografia nos cursos de pedagogia}

Ao entender o espaço geográfico como objeto de estudo da Geografia, compete ao seu estudo dois aspectos principais: o primeiro, a adoção de escalas, temporal e espacial; e o segundo, 
à luz das categorias de análise do espaço. É de posse dessas escalas e categorias que se podem fazer análises mais ajustadas quanto ao entendimento das relações e arranjos que o nutrem; por conseguinte, dos processos que dialogam e regem as dinâmicas do espaço geográfico.

As categorias, como paisagem, lugar, território e região, são entendidas, assim, como conceitos estruturadores do conhecimento geográfico. Na escola básica, esses conceitos perpassam (ou deveriam perpassar) os conteúdos a serem trabalhados pelos professores e alunos nos diferentes anos. ${ }^{7}$ Nesse sentido, os PCN de Geografia (Brasil, 1997, p. 75) enfatizam que:

No que se refere ao ensino fundamental, é importante considerar quais são as categorias da Geografia mais adequadas para os alunos em relação à sua faixa etária, ao momento da escolaridade em que se encontram e às capacidades que se espera que eles desenvolvam. Embora o espaço geográfico deva ser o objeto central de estudo, as categorias paisagem, território e lugar devem também ser abordadas, principalmente nos ciclos iniciais, quando se mostram mais acessíveis aos alunos, tendo em vista suas características cognitivas e afetivas.

Entende-se que o texto dos PCN aponta um caminho importante sobre os conceitos estruturadores do conhecimento geográfico a ser considerados no ensino de Geografia nos anos iniciais, tendo em vista a faixa etária dos alunos.

Para isso, entretanto, há de se considerar o papel irrefutável da formação inicial desses professores, ao passo que a presença/ausência desses conceitos durante sua formação pode comprometer a qualidade de sua atuação.

Logo, pergunta-se: $\bigcirc$ que pressupõe os PCN está ocorrendo nas salas de aula? Os cursos de Pedagogia estão preparando o futuro professor para ensinar Geografia pensando seu objeto de estudo e suas categorias de análise? Os conceitos estruturadores do conhecimento geográfico estão presentes nesses cursos?

A análise do conteúdo presente nas ementas permite inferir dados importantes a esse respeito.

Nas palavras de Callai (2014), sem a consideração da escala social de análise, corre-se o risco no ensino de Geografia de não se entenderem as dinâmicas (econômicas, políticas ou naturais) envolvidas no espaço territorializado.

Por consequência, os professores, juntamente com os seus alunos, devem buscar a aprendizagem significativa por intermédio da interlocução do conhecimento geográfico com o lugar onde vivem, sobrepondo-o e intercalando com outras escalas geográficas de análise como a nacional e a global. Afinal, como é sabido, nenhum lugar se explica por si só. Ele contém e está contido em contextos mais amplos (Brasil, 1997, p. 76). Entretanto, nota-se, pela análise da pauta de conteúdos para qual é voltada as ementas dos cursos de Pedagogia, que poucas trazem à luz as escalas geográficas. Apenas duas (e pertencentes ao mesmo curso) as abordam como "contexto global, nacional e local".

7 Embora a Geografia escolar seja uma criação particular e original da escola, que responde às finalidades sociais que the são próprias e diferentes da Geografia Acadêmica (Callai, 2011), entende-se a importância de ela se alimentar das bases teóricas desta. 


\section{Quadro 1 - Conteúdos que aparecem nas ementas das disciplinas de Geografia nos cursos de Pedagogia}

\begin{tabular}{|c|c|c|c|c|c|}
\hline \multirow{2}{*}{ Conteúdo } & \multicolumn{5}{|c|}{ Vezes em que aparece } \\
\hline & 1 & 2 & 3 & 4 & 5 ou mais \\
\hline \multicolumn{6}{|l|}{ Ensino de Geografia em uma visão interdisciplinar } \\
\hline \multicolumn{6}{|l|}{ Estudo Relaçăo Homem-Meio } \\
\hline \multicolumn{6}{|l|}{ Industrializaçăo } \\
\hline \multicolumn{6}{|l|}{ Leitura geográfica do mundo contemporâneo } \\
\hline \multicolumn{6}{|l|}{ Lugar } \\
\hline \multicolumn{6}{|l|}{ Natureza } \\
\hline \multicolumn{6}{|l|}{ Território } \\
\hline \multicolumn{6}{|l|}{ Trabalho de Campo e estudo de caso } \\
\hline \multicolumn{6}{|l|}{ Trabalho Humano } \\
\hline \multicolumn{6}{|l|}{ Didática do ensino de Geografia } \\
\hline \multicolumn{6}{|l|}{ Contexto global, nacional e local } \\
\hline \multicolumn{6}{|l|}{$\begin{array}{l}\text { Contextualizaçắo da prática pedagógica da Geografia nos } \\
\text { AIEF }\end{array}$} \\
\hline \multicolumn{6}{|l|}{ Currículo de Geografia } \\
\hline \multicolumn{6}{|l|}{$\begin{array}{l}\text { Diagnóstico e Crítica da atual realidade do ensino de } \\
\text { Geografia e das pesquisas na área }\end{array}$} \\
\hline \multicolumn{6}{|l|}{ Livro Didático e Paradidático } \\
\hline \multicolumn{6}{|l|}{ Meio Ambiente } \\
\hline \multicolumn{6}{|l|}{ Paisagem } \\
\hline \multicolumn{6}{|l|}{ Alfabetização/linguagem cartográfica } \\
\hline \multicolumn{6}{|l|}{ Conteúdo da Geografia } \\
\hline \multicolumn{6}{|l|}{ Espaço Geográfico } \\
\hline \multicolumn{6}{|l|}{ Materiais Didáticos } \\
\hline \multicolumn{6}{|l|}{ Métodos de ensino } \\
\hline \multicolumn{6}{|l|}{ Objeto de estudo (sem especificação) } \\
\hline \multicolumn{6}{|l|}{ PCN para o Ensino de Geografia/ Propostas curriculares } \\
\hline \multicolumn{6}{|l|}{ Conceitos e categorias da Geografia (sem especificação) } \\
\hline \multicolumn{6}{|l|}{$\begin{array}{l}\text { Diferentes fontes, linguagens e recursos no ensino de } \\
\text { Geografia }\end{array}$} \\
\hline Correntes, concepçőes e teorias do ensino de Geografia & & & & & \\
\hline
\end{tabular}

Fonte: Dados organizados por Silva (2017) a partir das ementas das unidades curriculares.

Em contrapartida, "correntes, teorias e concepções do ensino de Geografia" foi o mais notado entre as ementas das 11 disciplinas oferecidas, sendo citadas seis vezes. Conforme Gatti e Nunes (2009, p. 33), algumas poucas ementas das universidades públicas identificam o tratamento dispensado aos conteúdos específicos a serem ensinados nos anos iniciais do Ensino Fundamental. Isso se verifica na medida em que foi considerável o número de citações de "objetos, conceitos e categorias de Geografia", embora sem a especificação necessária para se conhecerem as que eram consideradas nos cursos.

A Cartografia, essencial para que o aluno desenvolva o "olhar espacial", método a ser usado para se estudar e compreender a realidade (Callai, 2009) é referida em apenas três ementas. Percebe-se, assim como os estudos realizados por Novaes (2006), que, apesar da possibilidade e importância de já, nos anos iniciais do Ensino Fundamental, o pedagogo iniciar a alfabetização cartográfica das crianças, a formação acadêmica dos cursos de Pedagogia não apresentam (nos) componentes curriculares elementos que corroboram para essa instrução. 
A formação inicial ganha contornos essenciais nesse aspecto, ao passo que, quanto mais bem instrumentalizado o professor, maior é a probabilidade de um ensino crítico e significativo nesses anos para tal alfabetização.

Entende-se que, para um professor ensinar Geografia, é necessário saber Geografia, sobretudo seu objeto de estudo e categorias de análise. Afinal, a prática é fundamentada na epistemologia. Assim, o reconhecimento do objeto de estudo da Geografia é o primeiro passo para uma reflexão teórica sobre fundamentos e métodos dessa ciência (Leão; Carvalho Leão, 2013, p. 83).

Em vista da presença das categorias de análise da Geografia, que são indicadas pelos PCN para serem trabalhadas nos ciclos iniciais tendo em vista as características cognitivas e afetivas dos alunos, pode-se categorizá-las a partir de três blocos: Conceitos e métodos da Geografia (não especificados); o de outros conceitos como: trabalho, natureza, industrialização, meio ambiente; e os conceitos estruturadores do conhecimento geográfico: Lugar, Paisagem, Território, além do Espaço Geográfico - objeto de estudo da Geografia (Brasil, 1997). Nota-se, entretanto, que os últimos aparecem apenas esporadicamente, Lugar e Território, uma vez cada e Paisagem duas vezes. $\bigcirc$ próprio Espaço Geográfico é abordado em apenas três das 11 ementas.

Seja como ciência, seja como matéria de ensino, a Geografia desenvolveu uma linguagem, um corpo conceitual que acabou por constituir-se numa linguagem geográfica. [...] Esta linguagem está permeada por conceitos que são requisitos para a análise dos fenômenos do ponto de vista geográfico (Cavalcanti, 1998, p. 88).

Nas palavras de Leão e Carvalho Leão (2013), ao se trabalhar com temas como relevo, hidrografia e população, é salutar saber que eles devem guardar estreita relação com o objeto de estudo da Geografia. Os professores atuantes nesse ensino precisam ter clareza de que esses conteúdos e as categorias mais gerais do conhecimento geográfico carregam em si a estrutura lógica dessa ciência.

Reforça-se, assim, a inegável importância de haver nessas disciplinas a relação entre os elementos teóricos da ciência e os procedimentos metodológicos. Nesse contexto, há de se desenvolver um ensino-aprendizagem pautado na articulação entre Teoria e Prática para além da racionalidade técnica apresentada anteriormente, para que a opção entre uma ou outra não incorra em uma formação superficial e sem densidade, que não contribui efetivamente para a formação docente almejada. Como afirma Freire (1996, p. 12), "A reflexão crítica sobre a prática se torna uma exigência da relação Teoria/Prática sem a qual a teoria pode ir virando blablablá e a prática, ativismo".

\section{Considerações finais}

Sabe-se que a formação inicial, não só no Brasil, mas no mundo, merece e precisa ser periodicamente repensada, sobretudo por seu caráter essencialmente dinâmico. Nesse sentido, o viés escolhido na pesquisa de mestrado na qual este texto se ampara foi pensar a formação docente no âmbito das propostas curriculares da formação inicial dos professores que atuarão nos anos iniciais do Ensino Fundamental no contexto da educação geográfica.

Diante do dilema (sobre o que ensinar aos graduandos nos cursos de Pedagogia), considera-se fundamental que eles conheçam a Ciência de referência e seus conceitos estruturadores, para que, cada vez mais e melhor, possam compreender a importância de seu ensino na Educação Básica. 
Concomitantemente, é necessária a clareza teórico-metodológica de que a construção do conhecimento, nessa faixa etária da aprendizagem (Aief), se concretiza com respeito aos alunos, sua leitura do mundo e seus conhecimentos prévios, fruto de suas experiências nos lugares onde vivem.

Parte-se da premissa de que conhecer o objeto de estudo e as categorias de análise da Geografia, assim como a alfabetização cartográfica, são pré-requisitos para que os alunos da Educação Básica, a seu tempo, compreendam o espaço onde vivem e se reconheçam como agentes construtores/transformadores desse espaço.

Nessa perspectiva, analisou-se a formação inicial oferecida nos cursos superiores de Pedagogia, modalidade presencial, instalados nas universidades públicas federais em Minas Gerais. $\bigcirc$ exame dos PPC, das ementas e da organização curricular permite concluir que eles não têm um padrão. Às vezes, as ementas apresentam textos genéricos, imprecisões ou insuficiências conceituais que não permitiram compreender o real tratamento dispensado à Geografia na respectiva unidade curricular. Na maioria das vezes, foram elaboradas como lista de conteúdos.

A cartografia aparece em apenas três das 11 ementas, já o conceito de escala geográfica ocorre em duas (do mesmo curso), como "contexto global, nacional e local".

Em vista da presença das categorias de análise da Geografia, nota-se que aparecem apenas esporadicamente. E se conclui que os conceitos estruturadores do conhecimento geográfico, defendidos pelos Parâmetros Curriculares Nacionais de Geografia (Brasil, 1997) como imprescindíveis ao ensino de Geografia nesses anos (Lugar, Paisagem, Território e o próprio Espaço Geográfico), não são prioridades nos cursos formadores.

Em vista da importância da formação inicial na qualificação do trabalho docente, considera-se salutar (re)pensá-la no tangente às áreas específicas e às consequências de sua presença/ ausência nas salas de aula dos cursos de Pedagogia, e, por conseguinte, nas salas de aula dos anos iniciais do Ensino Fundamental na Educação Básica.

\section{Referências}

BRAGA, M. C. B. Aprender e ensinar geografia: a visão de egressos do curso de pedagogia da UEFS (Universidade Estadual de Feira de Santana). Tese (Doutorado Em Educação)Universidade Federal de São Carlos, São Carlos, 2006.

BRASIL. Conselho Nacional de Educação. Diretrizes Curriculares Nacionais Gerais da Educação Básica. Brasilia, DF: MEC/SEB/Dicei, 2013.

BRASIL. Resolução CNE/CPn. 1, del5 de maio de 2006. Institui Diretrizes Curriculares Nacionais para o Curso de Graduação em Pedagogia licenciatura. Diário Oficial [da] República Federativa do Brasil, Brasília, DF, 16 maio 2006, p. 11. Seção 1. Disponível em: http://portal.mec.gov.br/cne/arquivos/pdf/rcp01_06.pdf. Acesso: 1 jan. 2012.

BRASIL. Secretaria de Educação Fundamental. Parâmetros curriculares nacionais: História, Geografia. Brasilia, DF: MEC/SEF, 1997. v. 5

BRASIL. Lei Federal n. 9.394, de 20 de dezembro de 1996. Estabelece as Diretrizes e Bases da Educação Nacional. Disponível em: http://www.planalto.gov.br/CCIVIL/LEIS/19394.htm. Acesso em: 26 set. 2015. 
BRZEZINSKI, I. Políticas contemporâneas de formação de professores para os anos iniciais do Ensino Fundamental. Educação \& Sociedade, Campinas, v. 29, n. 105, p. 1139-1166, set./dez. 2008. Disponível em: http://www.cedes.unicamp.br. Acesso em: 20 mar. 2016.

CALLAI, H. C. O livro didático no contexto dos processos de avaliação. OKARA Geografia em Debate, João Pessoa: DGEOC/CCEN/UFPB, v. 10, n. 2, p. 273-290, 2016. Disponível em: http://www.okara.ufpb.br. Acesso em: 14 dez. 2016.

CALLAI, H. C. O estudo do lugar como possibilidade de construção da identidade e pertencimento. In: CONGRESSO LUSO-AFRO-BRASILEIRO DE CIÊNCIAS SOCIAIS A questão social no novo milênio, 8., 16-18 set. 2014, Coimbra, PT. Anais... Coimbra, 2014. Disponível em: https://www.ces.uc.pt/lab2004/pdfs/HelenaCallai.pdf. Acesso em: 27 ago. 2015.

CALLAI, H. C. A geografia escolar - e os conteúdos da geografia. Anekumene - Geografía, Cultura y Educación, n. 1, p. 128-139, 2011.

CALLAI, H. C. A geografia ensinada: os desafios de uma educação geográfica. In: MORAIS, E. M. B.; MORAES, L. B. (Org.). Formação de professores: conteúdos e metodologias no ensino de geografia. Goiânia: Vieira, 2010. p. 15-37.

CALLAI, H. C. Estudar o lugar para compreender o mundo. In: Castrogiovanni (Org.). Ensino de Geografia: práticas e textualizações no cotidiano. 7. ed. Porto Alegre: Mediação, 2009. p. 83-131.

CALLAI, H. C. A articulação teoria-prática na formação do professor de geografia. In: SILVA, A. M. M.; MACHADO, L. B.; MELO, M. M. O; AGUIAR, M. C. C. (Org.). Educação formal e não formal, processos formativos, saberes pedagógicos: desafios para a inclusão social. Recife: Bagaço, 2006. p. 143-161.

CALLAI, H. C. Aprendendo a ler o mundo: a geografia nos anos iniciais do Ensino Fundamental. Cadernos Cedes, Campinas, v. 25, n. 66, p. 227-247, maio/ago. 2005. Disponível em: http://www.cedes.unicamp.br. Acesso em: 12 abr. 2012.

CAVALCANTI, L. S. A geografia escolar e a cidade. Campinas, SP: Papirus, 2008.

FREIRE, P. Pedagogia da autonomia: saberes necessários à prática educativa. São Paulo: Paz e Terra, 1996.

GARCÍA, C. M. Formação de professores: para uma mudança educativa. Porto: Porto, 1999. (Coleção Ciências da Educação Século XXI, 2.)

GATTI, B. A.; NUNES, M. M. R. (Org.). Formação de professores para o ensino fundamental: estudo de currículos das licenciaturas em pedagogia, língua portuguesa, matemática e ciências biológicas. São Paulo: FCC/DPE, 2009.

GÓMEZ, A. P. O pensamento prático do professor: a formação do professor como profissional reflexivo. In: NÓVOA, A. (Coord.). Os professores e a sua formação. 3a ed. Lisboa: Dom Quixote, 1997. p. 93-114.

IBGE. INSTITUTO BRASILEIRO DE GEOGRAFIA E ESTATÍSTICA. Censo Demográfico 2010: Resultados Gerais da Amostra. Rio de Janeiro: IBGE, 2010. 
Disponível em: http://biblioteca.ibge.gov.br/visualizacao/periodicos/99/cd_2010_ resultados_gerais_amostra.pdf. Acesso em: 26 fev. 2015.

LEÃO, V. P.; CARVALHO LEÃO, I. A. Metodologia do ensino de geografia. São João del-Rei, MG: UFSJ, 2013.

LIBÂNEO, J. C. O ensino da didática, das metodologias específicas e dos conteúdos específicos do ensino fundamental nos currículos dos cursos de pedagogia. Revista Brasileira de Estudos Pedagógicos, Brasilia, v. 91, n. 229, p. 562-583, set./dez. 2010. doi: https:// doi.org/10.24109/2176-6681.rbep.9li229.630.

LIBÂNEO, J. C. Pedagogia e pedagogos, para quê? 10a ed. São Paulo: Cortez, 2008.

LIBÂNEO, J. C. Diretrizes curriculares da pedagogia: imprecisões teóricas e concepção estreita da formação profissional de educadores. Educação $\boldsymbol{E}$ Sociedade, Campinas, v. 27 , n. 96, p. 843-876, out. 2006. Número especial. Disponível em: http://www.cedes.unicamp.br. Acesso em: 26 set. 2015.

NOVAES, I. F. A geografia nas séries iniciais do ensino fundamental: desafios da e para a formação docente. Dissertação (Mestrado em Geografia) - Universidade Federal de Uberlândia, Uberlândia, 2006.

NÓVOA, A. (Coord.). Os professores e a sua formação. 3a ed. Lisboa: Dom Quixote, 1997.

SILVA, S. M. A presença dos conceitos estruturadores do conhecimento geográfico nos cursos de pedagogia em Minas Gerais. São João del-Rei, 2017, 150 p. Dissertação (Mestrado em Geografia) - Universidade Federal de São João del-Rei, São João del-Rei, 2017.

SILVA, S. M.; LEÃO, V. P. Anos iniciais do Ensino Fundamental: por onde anda a geografia? Caderno de Geografia, PUC Minas, v. 26, n. 46, p. 382-395, 2016. doi: https:// doi.org/10.5752/P.2318-2962.2016v26n46p382.

SCHEIBE, L. Formação de professores no Brasil: uma herança histórica. Retratos da Escola, Brasília, v. 2, n. 2-3, p. 41-53, jan./dez. 2008.

\section{Contribuição dos autores:}

Samara Mirelly da Silva: concepção e desenho da pesquisa, coleta e processamento dos dados, análise e interpretação dos dados, redação do texto final, revisão e aprovação da versão final do trabalho.

Vicente de Paula Leão: concepção e desenho da pesquisa, análise e interpretação dos dados, redação do texto final, revisão e aprovação da versão final do trabalho.

Recebido em: 9 jan. 2018 Aprovado em: 31 ago. 2020 